\title{
Patient characteristics associated with treatment initiation among paediatric patients with Attention-Deficit/Hyperactivity Disorder symptoms in a naturalistic setting in Central Europe and East Asia
}

Jihyung Hong ${ }^{1 *}$, Diego Novick', Tamás Treuer², William Montgomery ${ }^{3}$, Virginia S Haynes ${ }^{4}$, Shenghu Wu ${ }^{5}$ and Josep Maria Haro ${ }^{6}$

\begin{abstract}
Background: Cultural views of Attention-Deficit/Hyperactivity Disorder (ADHD), differing healthcare systems and funding mechanisms, and the availability of mental health services can greatly influence the perceptions, diagnosis, and treatment of ADHD. There is, however, lack of information about treatment practice and the treatment decision-making process for ADHD, particularly in non-Western countries. Our study compared characteristics of paediatric patients newly diagnosed with ADHD symptoms who did and who did not initiate treatment, and also examined whether any differences varied by region in Central Europe and East Asia.

Methods: Data were taken from a 1-year prospective, observational study that included 1,068 paediatric patients newly diagnosed with ADHD symptoms. Clinical severity was measured using the Clinical Global Impression-ADHDSeverity (CGI-ADHD-S) scale and the Child Symptom Inventory-4 (CSI-4) checklist. Logistic regression was used to explore patient characteristics associated with treatment initiation (pharmacotherapy and/or psychotherapy) at baseline for each region.
\end{abstract}

Results: A total of $74.3 \%$ of patients initiated treatment at baseline (78.3\% in Central Europe and 69.9\% in East Asia). Of these, $48.8 \%$ started with both pharmacotherapy and psychotherapy in Central Europe, and only $17.1 \%$ did so in East Asia. The level of clinical severity was highest in the combination treatment group in Central Europe, but was highest in the psychotherapy only group in East Asia. In East Asia, treatment initiation was associated with being older, being male, and having a higher CGI-ADHD-S score. In Central Europe, treatment initiation was associated with parental psychological distress, having a higher CSI-4 score, and not being involved in bullying.

Conclusions: Although factors associated with treatment initiation differed to some extent between Central Europe and East Asia, clinical severity appeared to be one of the most important determinants of treatment initiation in both regions. However, the choice between pharmacotherapy and psychotherapy, either alone or in combination, varied substantially across the regions.

Keywords: ADHD, Treatment initiation, Patient characteristics, Central Europe, East Asia

\footnotetext{
* Correspondence: jihyung.hong.kr@gmail.com

'Eli Lilly and Company, Windlesham, Surrey, UK

Full list of author information is available at the end of the article
} 


\section{Background}

Attention-Deficit/Hyperactivity Disorder (ADHD) is a neurobehavioural condition, characterised by the core symptoms of inattention and/or hyperactivity/impulsivity [1]. It is among the most prevalent mental disorders in childhood and adolescence across countries and regions [2]. Although data on the prevalence of ADHD in nonWestern countries (e.g., Central Europe and East Asia) are limited, the available evidence suggests that prevalence rates in these regions are similar to those in Western countries, ranging from $7.5 \%$ to $12 \%$ among school-aged children and adolescents [3-7].

Treatment for ADHD typically involves both pharmacotherapy and psychoeducational/behavioural treatments, either alone or in combination [8-10]. Several international guidelines on ADHD support the use of these treatment options, although a discrepancy exists between the U.S. [10] and European guidelines in the treatment preferences for first-line therapy $[8,11]$. For example, the U.S. guidelines developed by the American Academy of Paediatrics recommend the first-line use of pharmacotherapy, preferably combined with behavioural therapies, for school-aged children and adolescents with ADHD, but only behavioural therapies for preschool-aged children [10], whereas the European guidelines developed by the European Network for Hyperkinetic Disorders and the UK guideline developed by the National Institute for Health and Care Excellence recommend that the use of drug treatments be reserved only for those with severe symptoms and impairments or when patients fail to respond to an initial trial of psychological treatments $[8,11]$. Although European guidelines are, in general, more conservative about the use of pharmacotherapy as a first-line therapy for ADHD due to concerns over potential adverse events during treatment with ADHD medications (albeit rare and mostly manageable [12]), these guidelines consider both pharmacotherapy and psychotherapy as important treatment options for ADHD and suggest that patient age and clinical severity are the most important clinical factors to consider when making treatment decisions for ADHD.

The limited available evidence on the factors associated with treatment initiation is largely consistent with these international guidelines $[13,14]$. Using data from a 2-year observational study in Europe, Falissard et al. found that the initiation of pharmacotherapy at the baseline visit was associated with more severe ADHD symptoms and impairments [13]; however, the study was primarily descriptive and did not examine the associations with other factors. The only study that has explicitly explored patient characteristics associated with the initiation of ADHD treatment was a study by Chen et al. based in the United States [14]. While they analysed the initiation of medication among patients with a new ADHD episode using Florida Medicaid claims data, the study was unable to assess the impact of clinical severity on treatment decision due to data constraints and also focused more on the choice between ADHD medications and other psychiatric medications in the treatment of ADHD. The study reported that the initiation of ADHD medications was associated with being older and being male, as well as other patient characteristics including race (White), rural dwelling, foster care, and the diagnosis by primary care physicians [14].

Although patient age and clinical severity are likely to play important roles in the treatment decision-making process for ADHD, a recent study based on the opinions of and feedback from international leaders in this area confirmed the great deal of variation in ADHD diagnosis and treatment practices across and within countries [15]. Cultural views on the disorder, differing healthcare systems and funding mechanisms, and the availability of mental health services were assumed to greatly influence perceptions, diagnosis, and treatment of ADHD. For example, the study indicated that as in the United States, Canadian health professionals tend to view "ADHD as an impairing, often life-long disorder that requires careful assessment and multimodal intervention" [15]. In addition, a wide range of pharmacological and psychosocial interventions are made accessible to the general population through the nationalised healthcare system. Meanwhile, ADHD is still greatly underdiagnosed and undertreated in many parts of the world due to the high levels of stigma attached to mental illness, lack of acceptance of ADHD as a disorder, limited access to services, lack of training in the treatment of ADHD among medical and mental health professionals, and the high acceptance of herbal treatments and homeopathy in some cultures. Although there is lack of empirical evidence on treatment practices for ADHD in non-Western countries, the role of clinical severity in the treatment decision-making process may be greater in these regions because the stigma attached to mental illness and the preference for homeopathic and herbal remedies are likely stronger, thereby the use of psychiatric treatments/medications is likely less accepted in these regions.

Using data from a 1-year, prospective, observational study involving 1,068 paediatric patients newly diagnosed with ADHD symptoms from Central Europe and East Asia, this study compared the demographic and clinical characteristics of those patients who did and did not initiate treatment in routine clinical practice in Central Europe and East Asia and examined whether any differences between them varied by region.

\section{Methods}

\section{Study design and patient sample}

This was a 12-month, international, prospective, noninterventional, observational study primarily designed to 
examine the treatment patterns and health outcomes among paediatric patients newly diagnosed with ADHD symptoms in actual clinical practice. From October 2005 to July 2006, fifty-eight psychiatrists and paediatricians enrolled a total of 1,068 paediatric patients from eight countries across Central Europe and East Asia (China $[\mathrm{n}=301]$, the Czech Republic [ $\mathrm{n}=50]$, Hungary $[\mathrm{n}=96]$, Romania [ $n=82]$, Slovakia [ $n=55]$, South Korea [ $n=$ 100], Taiwan [ $\mathrm{n}=101]$, and Turkey $[\mathrm{n}=283])$. This study followed the ethical standards of responsible local committees and regulations from the participating countries, was conducted in accordance with the ethical principles of the Declaration of Helsinki, and is consistent with good clinical practice when applicable to a study of this nature. Ethical Review Board (ERB) approval was obtained wherever required by local law for observational studies (see Additional file 1). The parents/guardians of all patients provided written informed consent, and the patients provided assent. Further details on the study design have been reported elsewhere [16-20].

Child and adolescent outpatients aged 6 to 17 years could participate in the study if they presented within the normal course of care with ADHD symptoms and had not been previously diagnosed with or treated for ADHD. The diagnosis of ADHD symptoms was made by an investigator using standard diagnostic criteria (Diagnostic and Statistical Manual of Mental Disorders-4th edition-text revision [DSM-IV-TR] [21] or International Classification of Diseases-10 [ICD-10] [22]). That is, in the clinical judgment of the investigator, at baseline the participating patients were required to have hyperactive, inattentive, or impulsive symptoms or problems associated with ADHD as described in the DSM-IV-TR or hyperkinetic disorders, disturbance of activity and attention, or hyperkinetic conduct disorder as described in the ICD-10. The study excluded those patients who had severe mental retardation (i.e., those unable to attend school due to mental disability), those who had epilepsy or schizophrenia, or those who were participating in a different study that included use of a treatment intervention or investigational drug.

Data collection for the study occurred during visits within the normal course of care. Baseline data were collected from the routine outpatient visit in which patients were enrolled. Subsequent data collection was targeted at 1 month after the baseline visit and then every 3 months (3, 6, 9, and 12 months) after the baseline visit. Patient demographics and clinical history were recorded at the baseline assessment. Clinical severity of ADHD symptoms were assessed by treating physicians at each visit using the Clinical Global Impressions-ADHD-Severity (CGI-ADHD-S) scale [23] and Category A of the Child Symptom Inventory-4 Parent Checklist (CSI-4) [24]. The physician-rated version, of which CSI-4 scores were recorded by the treating physicians in consultation with parents, was used after converting scores to norm-referenced standardised CSI-4 scores using U.S.-based population norms.

\section{Treatment cohorts}

Patients could be prescribed any treatment regimen by the treating physician. Treatment decisions were made solely at the discretion of the physician, patient, or parent/guardian and were independent of study participation. In actual practice, patients could receive no treatment/intervention, psychotherapy, pharmacotherapy, a combination of psychotherapy and pharmacotherapy, or other treatments. The most commonly prescribed medication at baseline was methylphenidate $(45.5 \%[n=486 / 1,068]$ of the total sample; $69.0 \%$ [ $n=486 / 704$ ] of patients who were prescribed at least one medication). Psychotherapy included formal sessions of psychoeducation and counselling, cognitive behavioural therapy, hypnotherapy, family therapy, or psychodynamic therapy that were conducted by a certified healthcare provider at a regular frequency for an acceptable length of time. Other treatments included educational interventions, speech therapy, occupational therapy, herbal therapy/homeopathy, informal hypnosis, psychomotor/physiotherapy, electroencephalogram biofeedback, diet exclusion, diet supplementation, and relaxation techniques. Further details on treatment patterns are available elsewhere [16].

Patients were categorised into two groups for the current analysis. The no treatment group included patients who received no ADHD treatments/interventions and patients who received other treatments at baseline. The treatment group included patients who were prescribed pharmacotherapy, psychotherapy, or both at baseline. As shown in Table 1, all three treatment groups (i.e., psychotherapy only, pharmacotherapy only, and both) had higher levels of clinical severity than the two no treatment groups (i.e., no treatments/interventions and other treatments). The level of clinical severity among patients who initiated psychotherapy only was highest in East Asia but was similar to those who initiated pharmacotherapy with/ without psychotherapy in Central Europe.

\section{Statistical analysis}

Mean patient age and clinical severity by different types of treatments or no treatments prescribed at baseline (i.e., no treatments/interventions, other treatments, psychotherapy only, pharmacotherapy only, and the combination of psychotherapy and pharmacotherapy) were first examined and compared using one-way analysis of variance. Baseline characteristics of the patients who did and did not initiate treatment (i.e., psychotherapy, pharmacotherapy, or both) at baseline were then summarised and compared using $t$ tests (for numerical variables) and chi-square tests (for categorical variables). 
Table 1 Mean (SD) patient age and clinical severity by type of treatments prescribed at baseline

\begin{tabular}{|c|c|c|c|c|c|c|}
\hline Variables & No TX & Other TX & Psycho & Pharmaco & Combi & $P$ value \\
\hline \multicolumn{7}{|l|}{ All } \\
\hline Patient age & $8.60(2.49)$ & $7.90(2.14)$ & $8.66(2.06)$ & $9.13(2.61)$ & $9.24(2.51)$ & $<0.001$ \\
\hline CGI-ADHD & $4.16(1.01)$ & $4.33(0.94)$ & $4.80(1.12)$ & $4.51(0.93)$ & $4.55(1.01)$ & $<0.001$ \\
\hline CSI-4 & $72.63(11.02)$ & $73.58(10.30)$ & $76.31(10.08)$ & 75.29 (10.49) & $78.65(10.43)$ & $<0.001$ \\
\hline \multicolumn{7}{|l|}{ East Asia only } \\
\hline Patient age & $8.60(2.66)$ & $7.61(1.98)$ & $9.05(2.15)$ & $9.20(2.58)$ & $8.95(2.41)$ & $<0.001$ \\
\hline CGI-ADHD-S & $4.01(0.86)$ & $4.50(0.95)$ & $5.23(0.90)$ & $4.52(0.93)$ & $4.65(0.99)$ & $<0.001$ \\
\hline CSI-4 & $71.21(10.95)$ & $73.22(9.38)$ & 76.25 (9.68) & $74.61(9.08)$ & $73.33(9.27)$ & 0.022 \\
\hline \multicolumn{7}{|c|}{ Central Europe only } \\
\hline Patient age & $8.59(2.32)$ & $8.64(2.38)$ & $8.34(1.95)$ & $9.04(2.66)$ & $9.32(2.54)$ & 0.037 \\
\hline CGI-ADHD-S & $4.30(1.11)$ & $3.91(0.75)$ & $4.46(1.16)$ & $4.49(0.93)$ & $4.53(1.01)$ & 0.041 \\
\hline CSI-4 & $73.99(10.96)$ & $74.50(12.55)$ & $76.35(10.49)$ & $76.25(12.16)$ & $80.14(10.27)$ & $<0.001$ \\
\hline
\end{tabular}

Abbreviations: SD standard deviation, ADHD attention-deficit/hyperactivity disorder, CGI-ADHD-S Clinical Global Impressions-ADHD-Severity, CSI-4 Child Symptom Inventory-4 Parent Checklist, TX treatment, Psycho psychotherapy only, Pharmaco pharmacotherapy only, Combi the combination of both psychotherapy and pharmacotherapy.

Logistic regression analysis was performed to explore patient characteristics associated with treatment initiation at baseline. The model included patient age, gender, age at first symptoms, region (Central Europe or East Asia), birth problems, family history of ADHD, and CGI-ADHD-S score. The model also included the following variables, but only if they appeared to be significant at $\mathrm{p}<0.1$ in simple logistic regressions: body mass index $(\mathrm{BMI})\left(\mathrm{kg} / \mathrm{m}^{2}\right)$, having other children living at home, mother having paid employment, father having paid employment, emotional health problems of parents/ guardians due to their children's behavioural problems, having been truant in the 4 weeks before baseline, having been involved in bullying (as a bully) in the 4 weeks before baseline, having primary care visits for behavioural problems in the 4 weeks before baseline, having been invited to social activities in the 4 weeks before baseline, and CSI- 4 score. All analyses were repeated for each region, with the same list of the variables included in the model for the whole sample. The interactions between each factor and region were also examined to check whether the behaviour of the factors in treatment initiation, statistically significantly, differs by region. Each interaction model included region, each specific factor, and their interaction term. It should however be noted that the statistical significance of these interaction terms could be more meaningfully interpreted when the factors exhibit different directions of associations with treatment initiation in the regional subgroup analyses. In this case, the p-values of the interaction terms can indicate whether the different associations observed between regions are indeed statistically significant. Otherwise, their interpretations could be less straightforward. For instance, their interaction terms could appear to be non-significant when the behaviour of the factors in treatment initiation is similar between regions but the characteristics of the factors themselves still differ by region.

Statistical analyses were conducted using SAS version 9.1 software [25].

\section{Results}

\section{Patient characteristics}

A total of 1,068 paediatric patients newly diagnosed with ADHD symptoms were included in this analysis $(n=566$ in Central Europe and $n=502$ in East Asia). Approximately three-quarters of these patients $(74.3 \%, \mathrm{n}=794)$ initiated pharmacotherapy and/or psychotherapy at baseline $(8.4 \%$ for psychotherapy only, $40.1 \%$ for pharmacotherapy only, and $25.8 \%$ for both) (Figure 1). The rate of treatment initiation was higher in Central Europe (78.3\%) than in East Asia $(69.9 \%)(p=0.002)$. This difference was mainly attributable to a higher rate of other treatments prescribed in East Asia (11.2\% in East Asia and 3.9\% in Central Europe) (Figure 1). Another notable difference between the two regions was a higher prescription rate for combined pharmacotherapy and psychotherapy in Central Europe (48.8\%) than in East Asia (17.1\%).

Table 1 summarises mean (standard deviation [SD]) patient age and mean (SD) clinical severity for the five treatment types prescribed at baseline in each region. In East Asia, the mean level of clinical severity was highest in patients who initiated psychotherapy only (CGI-ADHD-S, 5.23 [SD 0.90]; CSI-4, 76.25 [SD 9.68]), whereas it was lowest in a subgroup of patients who did not initiate any treatments/interventions (CGI-ADHD-S, 4.01 [SD 0.86]; CSI-4, 71.21 [SD 10.95]). Mean patient age was lowest in those with other treatments (7.61 years [SD 1.98]), followed by those with no treatments/interventions (8.60 [SD 2.66]). In Central Europe, the mean level of clinical severity was highest in a subgroup of patients who initiated combination 


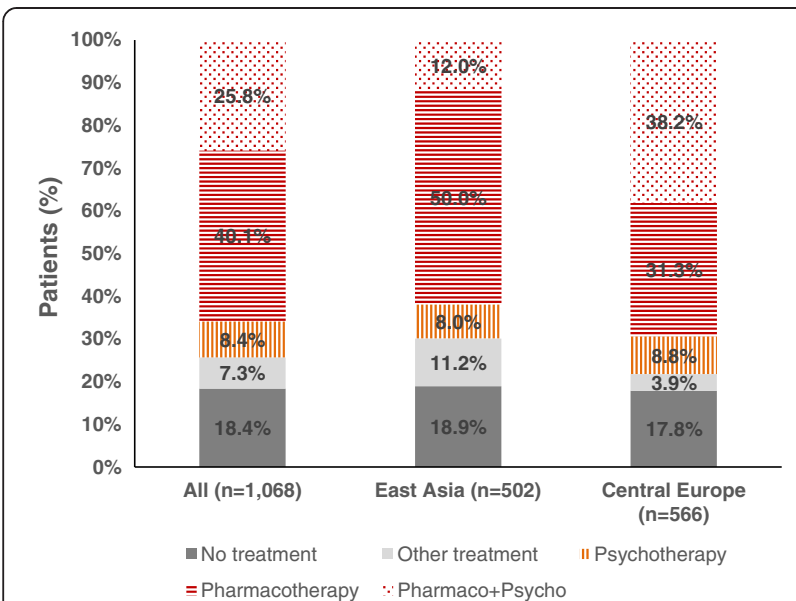

Figure 1 Type of treatments prescribed at baseline. Note that patients were categorised into two cohorts (no treatment and treatment) for the current analysis. The former includes patients who received no treatment and other treatment, and the latter includes patients who received pharmacotherapy and/or psychotherapy at baseline.

psychotherapy and pharmacotherapy (CGI-ADHD-S, 4.53 [SD 1.01]; CSI-4, 80.14 [SD 10.27]) and lowest in those who initiated other treatments or no treatments/interventions. Mean age was also highest in the combination group $(9.32$ [SD 2.54]) but lowest in the psychotherapy only group (8.34 [SD 1.95]).

The baseline patient characteristics by treatment initiation (i.e., psychotherapy and/or pharmacotherapy) are reported in Table 2. Patients who initiated treatment at baseline were more likely to be living in Central Europe, have had birth problems, have had primary care visits for behavioural problems in the 4 weeks before baseline, been truant in the 4 weeks before baseline, have parents/guardians experiencing emotional difficulties due to their child's behavioural problems, have mothers not in paid employment, and have been invited to social activities in the 4 weeks before baseline. In addition, these patients were older and had greater mean clinical severity (i.e., higher CGI-ADHD-S and CSI-4 scores).

\section{Patient characteristics associated with treatment initiation at baseline}

Table 3 shows the results of logistic regression, which examined patients' baseline characteristics associated with treatment initiation. At baseline, patients who initiated treatment tended to be older, have had birth problems, and have higher CGI-ADHD-S and CSI-4 scores, whereas those who did not initiate treatment tended to have been involved in bullying (as a bully) and have a working mother.

In East Asia, being older (odds ratio $[\mathrm{OR}]=1.17 ; 95 \%$ confidence interval $[\mathrm{CI}], 1.04,1.31 ; \mathrm{p}=0.009)$, being male $(\mathrm{OR}=1.95 ; 95 \%$ CI $1.02,3.73 ; \mathrm{p}=0.043)$, and having
Table 2 Baseline patient characteristics by treatment initiation at baseline

\begin{tabular}{|c|c|c|}
\hline Baseline characteristic & $\begin{array}{l}\text { No treatment } \\
(n=274)\end{array}$ & $\begin{array}{l}\text { Treatment } \\
(\mathrm{n}=794)\end{array}$ \\
\hline Age, mean $(S D)^{*}$ & $8.40(2.41)$ & $9.12(2.52)$ \\
\hline Male, \% & 81.68 & 82.38 \\
\hline Age at first symptoms, mean (SD) & $5.50(2.43)$ & $5.49(2.33)$ \\
\hline $\begin{array}{l}\text { Being from East Asia } \\
\text { (vs. Central Europe), \%* }\end{array}$ & 55.11 & 44.21 \\
\hline BMI (kg/m2), mean (SD) & $18.01(3.49)$ & $18.31(3.64)$ \\
\hline Birth problems, \%* & 19.35 & 29.91 \\
\hline Family history of ADHD, \% & 40.20 & 47.10 \\
\hline Having other children living at home, $\%$ & 54.25 & 57.47 \\
\hline CGI-ADHD-S, mean (SD)* & $4.21(0.99)$ & $4.56(0.98)$ \\
\hline $\begin{array}{l}\text { CSI-4 Category A (standardised), } \\
\text { mean (SD)* }\end{array}$ & $72.90(10.80)$ & $\begin{array}{l}76.55 \\
(10.53)\end{array}$ \\
\hline Paid employment (mother), \%* & 78.13 & 69.01 \\
\hline Paid employment (father), \% & 89.45 & 87.32 \\
\hline $\begin{array}{l}\text { Parental psychological distress due to } \\
\text { their children's behavioural problems, \%* }\end{array}$ & 38.15 & 51.26 \\
\hline $\begin{array}{l}\text { Being truant in the } 4 \text { weeks } \\
\text { before baseline, \%* }\end{array}$ & 4.18 & 8.75 \\
\hline $\begin{array}{l}\text { Being involved in bullying (as a bully) } \\
\text { in the } 4 \text { weeks before baseline, } \%\end{array}$ & 25.58 & 22.68 \\
\hline $\begin{array}{l}\text { Primary care visit for behavioural problems } \\
\text { in the } 4 \text { weeks before baseline, } \%^{*}\end{array}$ & 7.42 & 14.08 \\
\hline $\begin{array}{l}\text { Being invited to social activity in } \\
\text { the } 4 \text { weeks before baseline, \%* }\end{array}$ & 48.57 & 55.95 \\
\hline
\end{tabular}

*Significant at $\mathrm{p}<0.05$ Abbreviations: BMI body mass index, $A D H D$ attention-deficit/ hyperactivity disorder, CGI-ADHD-S Clinical Global Impressions-ADHD-Severity, CSI-4 Child Symptom Inventory-4 Parent Checklist, SD standard deviation.

higher CGI-ADHD-S scores (OR = 1.61; 95\% CI 1.19, 2.17; $\mathrm{p}=0.002)$ were associated with treatment initiation. In Central Europe, parental psychological distress $(\mathrm{OR}=4.33$; 95\% CI 1.91, 9.81; p < 0.001) and having higher CSI-4 scores $(\mathrm{OR}=1.04 ; 95 \% \mathrm{CI} 1.01,1.07 ; \mathrm{p}=0.022)$ were positively associated with treatment initiation, whereas being involved in bullying (as a bully) (OR $=0.27$; 95\% CI 0.13, $0.60 ; \mathrm{p}=0.001$ ) was inversely associated with treatment initiation at baseline. Notably, of these variables, being male and parental psychological distress exhibited different directions of odds ratios for treatment initiation in these regional subgroup analyses, and their interactions with region appeared to be statistically significant ( 0.034 for being male and $<0.001$ for parental psychological distress).

\section{Discussion}

There is now high-quality evidence supporting the efficacy and effectiveness of a range of pharmacological treatments in the management of children and adolescents with ADHD [8,10]. In addition, a number of 
Table 3 Factors associated with treatment initiation at baseline

\begin{tabular}{|c|c|c|c|c|c|c|c|c|c|c|}
\hline \multirow[b]{2}{*}{ Baseline factors } & \multicolumn{3}{|l|}{ All } & \multicolumn{3}{|c|}{ East Asia only } & \multicolumn{3}{|c|}{ Central Europe only } & \multirow{2}{*}{$\begin{array}{l}\text { Interaction } \\
\text { with region } \\
\text { P-value }\end{array}$} \\
\hline & $\mathrm{OR}^{+}$ & $95 \% \mathrm{Cl}$ & P-value & $\overline{\mathrm{OR}^{+}}$ & $95 \% \mathrm{Cl}$ & P-value & $\overline{\mathrm{OR}^{+}}$ & $95 \% \mathrm{Cl}$ & P-value & \\
\hline$\overline{\text { Age }}$ & 1.14 & $1.04,1.24$ & $0.005^{*}$ & 1.17 & $1.04,1.31$ & $0.009^{*}$ & 1.04 & $0.89,1.21$ & 0.599 & 0.227 \\
\hline Age at first symptoms & 1.00 & $0.91,1.10$ & 0.995 & 0.97 & $0.85,1.10$ & 0.633 & 1.02 & $0.87,1.19$ & 0.835 & 0.622 \\
\hline Being male & 1.24 & $0.74,2.07$ & 0.421 & 1.95 & $1.02,3.73$ & $0.043^{*}$ & 0.46 & $0.16,1.33$ & 0.154 & $0.034^{*}$ \\
\hline Being from East Asia & 0.87 & $0.56,1.36$ & 0.533 & - & - & - & - & - & - & - \\
\hline Having birth problems & 1.86 & $1.14,3.02$ & $0.013^{*}$ & 1.76 & $0.90,3.45$ & 0.099 & 1.74 & $0.79,3.80$ & 0.167 & 0.662 \\
\hline Family history of ADHD & 1.08 & $0.71,1.63$ & 0.730 & 1.23 & $0.71,2.14$ & 0.463 & 0.94 & $0.47,1.88$ & 0.856 & 0.948 \\
\hline Higher CGI-ADHD-S scores & 1.32 & $1.07,1.63$ & $0.010^{*}$ & 1.61 & $1.19,2.17$ & $0.002^{*}$ & 1.02 & $0.73,1.43$ & 0.915 & 0.185 \\
\hline Higher CSI-4 scores & 1.03 & $1.01,1.05$ & $0.013^{*}$ & 1.02 & $0.99,1.05$ & 0.189 & 1.04 & $1.01,1.07$ & $0.022^{*}$ & 0.877 \\
\hline Having a working mother & 0.60 & $0.38,0.94$ & $0.026^{*}$ & 0.68 & $0.38,1.22$ & 0.199 & 0.47 & $0.21,1.05$ & 0.066 & 0.291 \\
\hline Parental psychological distress & 1.20 & $0.80,1.81$ & 0.376 & 0.64 & $0.38,1.09$ & 0.103 & 4.33 & $1.91,9.81$ & $<0.001^{*}$ & $<0.001^{*}$ \\
\hline Being truant ${ }^{\S}$ & 1.47 & $0.56,3.82$ & 0.434 & 2.22 & $0.44,11.14$ & 0.334 & 1.83 & $0.49,6.77$ & 0.368 & 0.428 \\
\hline Being involved in bullying (as a bully) ${ }^{\S}$ & 0.55 & $0.36,0.85$ & $0.007^{*}$ & 0.82 & $0.47,1.44$ & 0.491 & 0.27 & $0.13,0.60$ & $0.001^{*}$ & 0.674 \\
\hline Primary care visit for behavioural problems ${ }^{\S}$ & 1.69 & $0.86,3.34$ & 0.130 & 1.90 & $0.81,4.49$ & 0.141 & 1.28 & $0.36,4.61$ & 0.702 & 0.912 \\
\hline Being invited to social activity ${ }^{\S}$ & 1.23 & $0.83,1.82$ & 0.309 & 1.39 & $0.83,2.33$ & 0.216 & 1.27 & $0.64,2.52$ & 0.496 & $0.019^{*}$ \\
\hline
\end{tabular}

${ }^{\mathrm{I} O R}>1$ indicates a positive association with treatment initiation. The models included patient age, gender, age at first symptoms, region, birth problems, a family history of ADHD, and CGI-ADHD-S score. The rest of the variables were also included as they appeared to be significant at $\mathrm{p}<0.1$ in simple regressions with the whole sample. The same list of the variables were also included in the subgroup analyses by region, except for the variable "region".

FThese $\mathrm{p}$-values are for the interactions between region and each specific variable taken from the models that included region, each specific variable, and their "interaction" term.

sBehaviour in the 4 weeks before baseline.

*The asterisks ${ }^{*}$ ) indicate $\mathrm{p}$-values of $<0.05$.

Abbreviations: ADHD attention-deficit/hyperactivity disorder, CGI-ADHD-S Clinical Global Impressions-ADHD-Severity, CSI-4 Child Symptom Inventory-4 Parent Checklist, $O R$ odds ratio, $\mathrm{Cl}$ confidence interval.

psychological interventions are also available as treatment options for ADHD, although their effects have been challenged by a recent meta-analysis limited to trials with "probably blind" assessment [26]. The findings of this large 1-year observational study, however, revealed that $25.7 \%$ of patients newly diagnosed with ADHD symptoms in Central Europe and East Asia did not initiate treatment (i.e., pharmacotherapy and/or psychotherapy) at baseline. This rate was higher in East Asia (30.1\%) compared with Central Europe (21.7\%), mainly due to a higher rate of other nonconventional treatments (e.g., herbal therapy) prescribed in East Asia. Nevertheless, clinical severity appeared to be one of the most important determinants of treatment initiation in both regions.

The role of clinical severity in treatment decision making may be even greater in East Asia than Central Europe. There were only three factors associated with treatment initiation in East Asia, which were being older, being male, and having higher clinical severity (measured by the CGIADHD-S). These three factors may indicate more severe clinical symptoms and a higher tolerability of drug treatments. Given the high acceptance of herbal treatments (traditional Chinese medicine) and high levels of stigma attached to mental illness in East Asia [15], it is possible that the initiation of formal treatment for ADHD is more conservative in this region, thereby its use is strictly limited to school-aged children and adolescents with severe clinical symptoms and impairments, as hypothesised.

However, it is noteworthy that the role of clinical severity or patient age does not appear to be obvious when making the decision between pharmacotherapy and psychotherapy in actual clinical practice in East Asia. Level of clinical severity was highest in a subgroup of patients who initiated psychotherapy only. This is somewhat inconsistent with international guidelines, which generally recommend the use of psychotherapy for milder ADHD and for younger children $[8,10,11]$. This might be partly due to the composition of our patient sample, who were patients newly diagnosed with ADHD symptoms, although the same pattern was not observed in Central Europe. Alternatively, this could reflect negative attitudes toward the use of medications for ADHD in East Asia, which might be much stronger there than in other parts of the world [27].

Clinical severity was also associated with treatment initiation at the baseline visit in Central Europe. Although it was highest in the subgroup of patients who initiated both psychotherapy and pharmacotherapy, $48.8 \%$ of patients started with the combination treatment at baseline, despite the fact that patients were all "newly" diagnosed with ADHD; this rate is much higher than that 
for East Asia (17.1\%). This is another geographical discrepancy in treatment practices that needs to be further investigated.

In addition to clinical severity, parental psychological distress due to their child's behavioural problems was also strongly associated with treatment initiation in this region. Although this variable could, in part, reflect the level of clinical severity of their affected child, it is not clear why this relationship was not observed in East Asia. In fact, parental psychological distress was inversely associated with treatment initiation in East Asia, although the association was not statistically significant $(\mathrm{OR}=0.64 ; 95 \%$ CI $0.38-1.09 ; \mathrm{p}=0.103)$. The interaction between region and parental psychological distress, however, still appeared to be statistically significant $(\mathrm{p}<0.001)$. Interestingly, previous research using the same data found that parental psychological distress was associated with medication nonadherence during follow-up in East Asia but not in Central Europe [20]. The Taiwanese study by Gau et al. also reported similar findings [28].

These seemingly contradictory findings may imply that different mechanisms underlie the impacts and causes of parental psychological distress in these regions. In Central Europe, parental psychological distress may indicate a greater need for professional help on their affected child and could be one of the main determinants of the decision to seek help, whereas in East Asia, the impacts and causes of parental psychological distress could be more complex. Many parents of children and adolescents with ADHD in East Asia tend to take personal responsibility for their child's behavioural problems and often have negative attitudes toward the use of medications for ADHD [27]. In East Asia, parents who also take heavy responsibility for their child's problems and extensively intervene to mediate behaviour are also more likely to be those who have psychological distress caused by their child's behavioural problems. It is possible that these types of parents are more conservative in the use of medication for their child's ADHD symptoms and are willing to initiate treatments only when their child's symptoms are sufficiently severe and cannot be appropriately controlled by their own interventions. They may also stop such treatments more easily once their child's symptoms improve, potentially leading to a higher level of medication nonadherence in East Asia. Further research, culturally sensitive, is required to better understand the role of parental psychological distress in the treatment of ADHD.

Our study also found an inverse association between being involved in bullying (as a bully) and treatment initiation at baseline in Central Europe. It should be noted that a similar association was also observed in East Asia, but it was not statistically significant $(\mathrm{OR}=$
0.82; 95\% CI 0.47-1.44; $\mathrm{p}=0.491)$. Although the reason for this inverse association is not clear, it is possible that given a higher possibility of other comorbid conditions among these patients (e.g., conduct disorder), clinicians could have needed more time to observe their symptoms before making a correct diagnosis and subsequent treatment plans. In addition, the use of stimulants, which were the only medications (or dominant medications) available for the treatment of ADHD in many countries in Central Europe and East Asia at the time this observational study was conducted, might have been discouraged for these children as first-line therapy due to potential risks of drug abuse or diversion.

However, several limitations of this study should be taken into account when interpreting these results. Firstly, given its observational design, the associations found in our study do not imply causal relationships. Secondly, the patients included in our study were diagnosed with the symptoms of ADHD, not necessarily with ADHD itself. The broader inclusion criteria were designed to observe and describe the similarities and differences in actual treatment practices and prescription patterns across several countries in Central Europe and East Asia. Although this is not a limitation in the context of our study, the role of clinical severity in treatment decision making could have been greater with such patients because they are potentially more heterogeneous in terms of symptom severity. Thirdly, the treatment initiation can also be influenced by the socioeconomic status of patients (e.g., income, insurance), especially in Central Europe and East Asia, where a high level of patient cost-sharing is common. However, due to data constraints, our study was unable to assess their impact on treatment initiation. Finally, although this observational study included more than one thousand patients, they may not be representative of the paediatric patients with ADHD symptoms in Central Europe and East Asia.

\section{Conclusions}

Our findings indicate systematic differences in patient characteristics between patients who did and did not initiate treatment (pharmacotherapy and/or psychotherapy) at baseline in the treatment of ADHD symptoms. Although factors associated with treatment initiation differed to some extent between Central Europe and East Asia, clinical severity appeared to be one of the most important determinants of treatment initiation in both regions but was possibly more so in East Asia. However, the choice between pharmacotherapy and psychotherapy, either alone or in combination, varied substantially across the regions. 


\section{Additional file}

Additional file 1: A list of all ethical review boards that approved the B4Z-VI-B004 observational study.

\section{Competing interests}

Jihyung Hong is a consultant for Eli Lilly and Company. Diego Novick, Tamás Treuer, Virginia S. Haynes, and Shenghu Wu are employees of Eli Lilly and Company Limited. Josep Maria Haro has acted as a consultant, received grants, or acted as a speaker in activities sponsored by the following companies: Astra-Zeneca, Eli Lilly and Company, Glaxo-Smith-Kline, and Lundbeck

\section{Authors' contributions}

$J \mathrm{H}$ conducted the statistical analysis and drafted the manuscript. DN, TT, WM, VSH, SW and JMH participated in the design of the present study and provided critical review of the manuscript. All authors have read and approved the final manuscript.

\section{Acknowledgments}

The study was sponsored by Eli Lilly and Company.

\section{Author details}

${ }^{1}$ Eli Lilly and Company, Windlesham, Surrey, UK. ${ }^{2}$ Eli Lilly and Company, Neuroscience Research, Budapest, Hungary. ${ }^{3}$ Eli Lilly Australia Pty Ltd, West Ryde, Australia. ${ }^{4}$ Eli Lilly and Company, Indianapolis, IN, USA. ${ }^{5}$ Eli Lilly China, Shanghai, China. ${ }^{6}$ Parc Sanitari Sant Joan de Déu, Fundació Sant Joan de Déu, CIBERSAM, Universitat de Barcelona, Barcelona, Spain.

Received: 28 January 2014 Accepted: 16 October 2014

Published online: 30 October 2014

\section{References}

1. Biederman J, Faraone SV: Attention-deficit hyperactivity disorder. Lancet 2005, 366(9481):237-248.

2. Polanczyk GV, Willcutt EG, Salum GA, Kieling C, Rohde LA: ADHD prevalence estimates across three decades: an updated systematic review and meta-regression analysis. Int J Epidemiol 2014, 43(2):434-442.

3. Chae PK, Jung HO, Noh KS: Attention deficit hyperactivty disorder in Korean juvenile delinquents. Adolescence 2001, 36(144):707-725.

4. Ersan EE, Dogan O, Dogan S, Sumer H: The distribution of symptoms of attention-deficit/hyperactivity disorder and oppositional defiant disorder in school age children in Turkey. Eur Child Adolesc Psychiatry 2004, 13(6):354-361

5. Gau SS, Chong MY, Chen TH, Cheng AT: A 3-year panel study of mental disorders among adolescents in Taiwan. Am J Psychiatry 2005, 162(7):1344-1350.

6. Takahashi K, Miyawaki D, Suzuki F, Mamoto A, Matsushima N, Tsuji H, Horino A, Ballas PA, Kiriike N: Hyperactivity and comorbidity in Japanese children with attention-deficit/hyperactivity disorder. Psychiatry Clin Neurosci 2007, 61(3):255-262

7. Hirfanoglu T, Soysal AS, Gucuyener K, Cansu A, Serdaroglu A: A study of perceptions, attitudes, and level of knowledge among pediatricians towards attention-deficit/hyperactivity disorder. Turk J Pediatr 2008, 50(2):160-166

8. Taylor E, Dopfner M, Sergeant J, Asherson P, Banaschewski T, Buitelaar J, Coghill D, Danckaerts M, Rothenberger A, Sonuga-Barke E, Steinhausen HC, Zuddas A: European clinical guidelines for hyperkinetic disorder - first upgrade. Eur Child Adolesc Psychiatry 2004, 13(Suppl 1):17-130.

9. Brown RT, Amler RW, Freeman WS, Perrin JM, Stein MT, Feldman HM, Pierce K, Wolraich ML: Treatment of attention-deficit/hyperactivity disorder: overview of the evidence. Pediatrics 2005, 115(6):e749-e757

10. Subcommittee on Attention-Deficit/Hyperactivity Disorder, Steering Committee on Quality Improvement and Management, Wolraich M, Brown L, Brown RT, DuPaul G, Earls M, Feldman HM, Ganiats TG, Kaplanek B, Meyer B, Perrin J, Pierce K, Reiff M, Stein MT, Visser S: ADHD: clinical practice guideline for the diagnosis, evaluation, and treatment of attention-deficit/hyperactivity disorder in children and adolescents. Pediatrics 2011, 128(5):1007-1022.

11. National Institute for Health and Care Excellence: Attention deficit hyperactivity disorder. Diagnosis and management of ADHD in children, young people and adults. NICE clinical guideline 72. London: NICE; 2008.
12. Cortese S, Holtmann M, Banaschewski T, Buitelaar J, Coghill D, Danckaerts M, Dittmann RW, Graham J, Taylor E, Sergeant J, on behalf of the European ADHD Guidelines Group: Practitioner Review: Current best practice in the management of adverse events during treatment with ADHD medications in children and adolescents. J Child Psychol Psychiatry 2013, 54(3):227-246

13. Falissard B, Coghill D, Rothenberger A, Lorenzo M: Short-term effectiveness of medication and psychosocial intervention in a cohort of newly diagnosed patients with inattention, impulsivity, and hyperactivity problems. J Atten Disord 2010, 14(2):147-156.

14. Chen CY, Gerhard T, Winterstein AG: Determinants of initial pharmacological treatment for youths with attention-deficit/hyperactivity disorder. J Child Adolesc Psychopharmacol 2009, 19(2):187-195.

15. Hinshaw SP, Scheffler RM, Fulton BD, Aase H, Banaschewski T, Cheng W, Mattos P, Holte A, Levy F, Sadeh A, Sergeant JA, Taylor E, Weiss MD: International variation in treatment procedures for ADHD: social context and recent trends. Psychiatr Serv 2011, 62(5):459-464.

16. Martenyi F, Treuer T, Gau SS, Hong SD, Palaczky M, Suba J, Tiberiu M, Uhlikova P, Xu T, Zoroglu S, Gadow KD, Walton R, Harrison G: Attentiondeficit/hyperactivity disorder diagnosis, co-morbidities, treatment patterns, and quality of life in a pediatric population in central and eastern Europe and Asia. J Child Adolesc Psychopharmacol 2009, 19(4):363-376.

17. Martenyi F, Zavadenko NN, Jarkova NB, Yarosh AA, Soldatenkova VO, Bardenstein LM, Kozlova IA, Neznanov NG, Maslova OI, Petrukhin AS, Sukchotina NK, Zykov VP: Atomoxetine in children and adolescents with attention-deficit/hyperactivity disorder: a 6-week, randomized, placebocontrolled, double-blind trial in Russia. Eur Child Adolesc Psychiatry 2010, 19(1):57-66.

18. Martenyi F, Zheng Y, Huang YS, Lee YS, Walton R, Harrison G, Treuer T: A prospective observational study of attention-deficit hyperactivity disorder in Asia: baseline characteristics of symptom severity and treatment options in a paediatric population. East Asian Archives Psychiatry 2010, 20(2):76-86.

19. Goetz M, Yeh C-B, Ondrejka I, Akay A, Herczeg I, Dobrescu I, Kim BN, Jin X, Riley AW, Martenyi F, Harrison G, Treuer T: A 12-month prospective, observational study of treatment regimen and quality of life associated with ADHD in central and eastern europe and eastern Asia. J Atten Disord 2012, 16(1):44-59.

20. Hong J, Novick D, Treuer T, Montgomery W, Haynes VS, Wu S, Haro JM: Predictors and consequences of adherence to the treatment of pediatric patients with attention-deficit/hyperactivity disorder in Central Europe and East Asia. Patient Preference Adherence 2013, 7:987-995.

21. APA: Diagnostic and statistical manual of mental disorders (4th edition; text revision). Washington, DC: American Psychiatric Association (APA); 2000.

22. World Health Organization: The ICD-10 Classification of Mental and Behavioural Disorders. Clinical descriptions and diagnostic guidelines. Geneva: WHO; 1992.

23. Guy W: ECDEU assessment manual for psychopharmacology (Revised). Bethesda, MD: U.S. Department of Health, Education and Welfare; 1976.

24. Gadow KD, Sprafkin J: Childhood Symptom Inventory 4. Screening and Norms Manual. Stony Brook, NY: Checkmate Plus; 2002.

25. SAS Institute Inc.: SAS 9.1 Software. Cary, North Carolina: SAS Institute Inc.

26. Sonuga-Barke EJ, Brandeis D, Cortese S, Daley D, Ferrin M, Holtmann M, Stevenson J, Danckaerts M, van der Oord S, Dopfner M, Dittmann RW, Simonoff E, Zuddas A, Banaschewski T, Buitelaar J, Coghill D, Hollis C, Konofal E, Lecendreux M, Wong IC, Sergeant J: Nonpharmacological interventions for ADHD: systematic review and meta-analyses of randomized controlled trials of dietary and psychological treatments. Am J Psychiatry 2013, 170(3):275-289.

27. Moon SY: Cultural perspectives on attention deficit hyperactivity disorder: A comparison between Korea and the U.S. J Int Bus Cult Stud 2011, 6:1.

28. Gau SS, Shen HY, Chou MC, Tang CS, Chiu YN, Gau CS: Determinants of adherence to methylphenidate and the impact of poor adherence on maternal and family measures. J Child Adolesc Psychopharmacol 2006, 16(3):286-297

\section{doi:10.1186/s12888-014-0304-x}

Cite this article as: Hong et al:: Patient characteristics associated with treatment initiation among paediatric patients with Attention-Deficit/ Hyperactivity Disorder symptoms in a naturalistic setting in Central Europe and East Asia. BMC Psychiatry 2014 14:304. 